\title{
Mechanism of Sodium Valproate Combined with Decitabine in Inhibiting Hepatocellular Carcinoma Cells Epithelial-Mesenchymal Transition and Invasion and Metastasis Based on p38 Mitogen-Activated Protein Kinases/Heat Shock Protein 27 Regulating Proliferation by p53 Pathway
}

F. GAO, JI HONG YANG, BO LIU, RUI ZHANG, MENG ZHANG AND Y. GENG*

Department of Hepatobiliary Surgery, Affiliated Hospital of Hebei University, Baoding, Hebei 071000, China

Gao et al.: Mechanism of Sodium Valproate Combined with Decitabine in Inhibiting Hepatocellular Carcinoma Cells

Sodium valproate combined with decitabine can inhibit cancer by inhibiting the invasion and metastasis of liver cancer cells of which the mechanism is not yet clear. In this study, valproic acid and decitabine were used during the culture of liver cancer cell that is human hepatocarcinoma cell line SMMC-7721 and the p38 mitogen-activated protein kinase activator anisomycin was added. Western blot was used to detect the expression of E-cadherin and vimentin proteins. Transwell experiment was used to detect the migration and invasion ability of liver cancer cells. Quantitative reverse transcription polymerase chain reaction and western blot were used to detect p38 mitogen-activated protein kinase/heat shock protein 27 signaling pathway expression changes and p53 expression levels. The results show that the combination of valproic acid and decitabine can significantly reduce the invasion and metastasis ability of SMMC-7721 cells and the expression of vimentin protein, occurrence of epithelial-mesenchymal transition and p38 mitogen-activated protein kinase/phospho-p38 mitogen-activated protein kinase/heat shock protein 27/phospho heat shock protein 27. At the same time, it increases the expression of E-cadherin protein and the expression level of p53 $(p<0.05)$ and the $\mathbf{p 3 8}$ mitogen-activated protein kinase activator anisomycin can inhibit the mentioned effects. These data show that the inhibition of epithelial-mesenchymal transition and invasion and metastasis of liver cancer cells may be achieved by increasing the expression of p53 which is through inhibiting the expression of p38 mitogen-activated protein kinase/heat shock protein 27 and its phosphorylation level when valproic acid and decitabine is combined.

Key words: Decitabine, p38 mitogen-activated protein kinase, heat shock protein 27, sodium valproate

Liver cancer, mainly divided into hepatocellular carcinoma and cholangiocarcinoma, is the seventh most common cancer worldwide and the fourth leading cause of cancer death ${ }^{[1,2]}$, especially in East Asia, where the mortality rate of liver cancer is the highest ${ }^{[3,4]}$. In the progress of liver cancer, genetic and epigenetic factors play a key role and DNA hypomethylation in epigenetic factors has been proven to be improved by drugs ${ }^{[5]}$. Both sodium valproate and decitabine (DAC) can inhibit DNA methyl transferase, histone deacetylation ${ }^{[6]}$ and DNA (cytosine-5)-methyltransferase 1 (DNMT1)
[7], causing DNA demethylation, thereby exerting anti-cancer effects ${ }^{[8]}$. Valproic Acid (VPA) has been used in clinical trials ${ }^{[9]}$, whose combined use with other chemotherapeutics can improve the anticancer effect $^{[10-13]}$. Studies have shown that sodium valproate combined with DAC can inhibit the development of cancer by inhibiting the invasion and metastasis of liver cancer cells of which the mechanism is not clear and needs to be explored.

Heat shock protein, as a stress-responsive protein, which can be produced under the high temperature

*Address for correspondence

E-mail: gdwkgy@sina.cn 
stress and pathological conditions is a kind of molecular chaperone. Heat shock protein 27 (Hsp27) is a low molecular weight heat shock protein that can bind to misfolded proteins and transfer it to Adenosine Triphosphate (ATP) dependent heat shock proteins for protein refolding or transfer to a protein degradation system $^{[14]}$, related to cell growth and apoptosis, tumor development and metastasis, drug resistance and other functions. The chaperone function of Hsp27 is regulated by phosphorylation and depends on oligomerization. When the cell is under stress, the expression of Hsp27 increases and phosphorylation occurs, making Hsp27 active and performing some of its functions. Protein phosphorylation is a major modification of proteins. After Hsp27 phosphorylation, large polymers will form small tetramers ${ }^{[15]}$. Hsp27 stress-related phosphorylation is usually triggered and catalyzed by p38 Mitogen-Activated Protein Kinase (MAPK) [16,17]. MAPK can transform extracellular stimuli into various cellular responses, thereby playing a key role in cellular processes such as cell proliferation, migration, differentiation and apoptosis ${ }^{[18]}$. The MAPK signaling pathway is regulated by three characteristic kinases, including Mitogen Activated Protein Kinase Kinase Kinase (MAP3K), Mitogen-Activated Protein Kinase Kinase (MAP2K) and MAPK. The target molecule is phosphorylated in the MAPK pathway. The activated MAP3K transfers the phosphate group from MAP3K to activated MAP2K and the activated MAP2K is further phosphorylated and activate MAPK, the phosphate group is transferred from MAP2K to MAPK ${ }^{[19]}$.

Studies have shown that the MAPK signaling pathways are mainly Extracellular signal-Regulated Kinase 1/2 (ERK1/2), c-Jun N-terminal Kinase (JNK)/StressActivated Protein Kinases (SAPK), p38, ERK3/ ERK4 and ERK5 ${ }^{[20]}$. And p38 MAPK is a key protein activated by a variety of inflammatory mediators and environmental stress, which can be selectively activated by MAP2K and plays an important role in proliferation, differentiation and survival ${ }^{[21]}$. Latest studies have shown that the p38 MAPK/Hsp27 signaling pathway is related to a variety of diseases, especially cancer which can be used as a cancer treatment target ${ }^{[22,23]}$.

Tumor protein p53 (p53) gene is a kind of tumor suppressor gene, which can be activated by a variety of signaling pathways. Activated p53 further activates a variety of downstream genes and eliminates damaged cells ${ }^{[2]}$. The $\mathrm{p} 53$ pathway is a natural protective barrier in the human body, protecting the body from DNA damage, repairing defects and preventing cancer. Based on the fact that the transcriptional activity of p53 is regulated by Hsp2 $7^{[25,26]}$ shown by studies, we explore the mechanism of sodium valproate combined with DAC in inhibiting the Epithelial-Mesenchymal Transition (EMT) and invasion and metastasis of liver cancer cells by blocking the p38 MAPK/Hsp27 signaling pathway with the help of the p38 MAPK activator anisomycin.

\section{MATERIALS AND METHODS}

\section{Cell culture:}

Culture, liver cancer/human hepatocarcinoma cell line (SMMC-7721) with Roswell Park memorial institute (RPMI) 1640 medium containing $10 \%$ fetal bovine serum (FBS), 100 kilounits per liter (kU/l) penicillin and $100 \mathrm{kU} / 1$ streptomycin and place it in a $37^{\circ}, 5 \%$ $\mathrm{CO}_{2}$ incubator and change the liquid culture every $3 \mathrm{~d}$.

\section{Grouping:}

The log phase cells were divided into three groups. The control group was given the same amount of Dimethyl Sulfoxide (DMSO); the treatment group was given $1.0 \mathrm{mmol} / 1 \mathrm{VPA}+5.0 \mathrm{mmol} / 1 \mathrm{DAC}$ for 48 $\mathrm{h}$; the treatment + SB203580 (specific inhibitors of $\mathrm{p} 38$ MAPK) group were given $1.0 \mathrm{mmol} / 1 \mathrm{VPA}+5.0 \mathrm{mmol} / 1$ DAC after pretreatment with 338 MAPK activator anisomycin,

\section{Quantitative Reverse Transcription Polymerase Chain Reaction (RT-qPCR):}

Use Trizol kit to extract total RNA from cells, take the preserved cells and carefully pour away the cell culture medium. Wash 3 times with sterile Phosphate Buffered Saline (PBS), transfer to ribonuclease (RNase), Free Eppendorf (EP) tube, add $500 \mu \mathrm{l}$ Trizol reagent, mix well and let stand for $5 \mathrm{~min}$ at room temperature to fully lyse. Centrifuge at $12000 \mathrm{~g}$ for $10 \mathrm{~min}$ at $4^{\circ}$, transfer the supernatant to a new RNase-free EP tube, add 100 $\mu l$ of chloroform, pipette several times to mix well and let it stand at room temperature for $10 \mathrm{~min}$. Centrifuge at $12000 \mathrm{~g}$ at $4^{\circ}$ for $15 \mathrm{~min}$. After layering the liquid in the EP tube, transfer the upper transparent layer to a new RNase-free EP tube, add $100 \mu \mathrm{l}$ of isopropanol, pipette several times to mix well and let it stand on ice for $20 \mathrm{~min}$. Centrifuge at $12000 \mathrm{~g}$ for $15 \mathrm{~min}$ at $4^{\circ}$. After centrifugation, RNA precipitates and adheres to the bottom of the EP tube. Discard the supernatant, add $500 \mu \mathrm{l}$ of $75 \%$ ethanol and mix by pipetting. Centrifuge at $12000 \mathrm{~g}$ for $10 \mathrm{~min}$ at $4^{\circ}$, discard the supernatant and repeat this step once. The last piece of Diethyl Pyrocarbonate (DEPC) water is used to dissolve RNA for storage and the concentration and purity of the RNA 
solution are determined by UV absorption. Remove genomic DNA (gDNA) according to the steps of Takara gDNA eraser genome removal kit and synthesize target gene complementary DNA (cDNA) according to the instructions of the reverse transcription kit. The system is $5 \times$ Primescript RT master mix, $4 \mu \mathrm{l}$; RNA, $1 \mu \mathrm{g}$; supplement the reaction system to $20 \mu \mathrm{l}$ with RNAse free double distilled water $\left(\mathrm{ddH}_{2} \mathrm{O}\right)$. The reaction conditions were $37^{\circ}, 15 \mathrm{~min} ; 85^{\circ}, 5 \mathrm{~s}$ and stored at $-20^{\circ}$ after completion. Configure the RT-qPCR reaction system according to the RT-qPCR kit: SYBR green 1 dye $10 \mu \mathrm{l}$, target gene upstream and downstream primer sequence $1 \mu \mathrm{l}$, Taq polymerase $2 \mu \mathrm{l}$, cDNA $5 \mu \mathrm{l}$, dd $\mathrm{d}_{2} \mathrm{O}$ $30 \mu \mathrm{l}$, total volume $50 \mu \mathrm{l}$, the final PCR product and DNA ladder electrophoresis and staining on a $2 \%$ agarose gel is used to detect whether the product is a single specific amplified band and the result is expressed by the quantitative method $2^{-\Delta \Delta C T}$.

\section{Transwell assay:}

The cells were digested with trypsin and centrifuged. Then they were resuspended and washed twice in RPMI-1640 medium with $10 \%$ FBS to remove the trace serum contained in the cell suspension. 600 $\mu 1$ RPMI-1640 medium containing $10 \%$ FBS was added to the lower chamber of the transwell chamber. RPMI-1640 medium adjusts the final concentration of each group of cells in the logarithmic growth phase to $1 \times 10^{5} / \mathrm{ml}$, pipette and add to the upper chamber of the transwell chamber, $100 \mu \mathrm{l}$ per tank and incubate in a $\mathrm{CO}_{2}$ incubator for $24 \mathrm{~h}$ then it can be terminated. Take out the upper chamber, aspirate the medium, wash twice with PBS and wipe the cells that have not passed through the bottom of the upper chamber with a cotton swab, then fix it in $4 \%$ formaldehyde for $10 \mathrm{~min}$ and then wash twice with PBS $0.1 \%$, stain with crystal violet for $30 \mathrm{~min}$. Wash with PBS and observe the cell migration ability under a microscope.

Cell invasion experiments need to add matrigel to the transwell chamber for humidification and the rest of the steps are the same as above.

\section{Western blot:}

Harvest the cells into an EP tube, wash ice with PBS to remove the remaining medium, add Radioimmunoprecipitation Assay (RIPA) cell lysate, lyse the cells ultrasonically, stand on ice for $30 \mathrm{~min}$, centrifuge at $16000 \mathrm{~g}$ at $4^{\circ}$ for $10 \mathrm{~min}$ and collect the supernatant to obtain the protein solution. Determine the concentration of total protein solution with Bicinchoninic Acid (BCA) protein quantification kit.
Prepare $12 \%$ separating gel and $5 \%$ concentrated gel according to the Sodium Dodecyl-Sulfate Polyacrylamide Gel Electrophoresis (SDS-PAGE) gel preparation kit, adjust the concentration of the extracted protein solution to $1 \mathrm{mg} / \mathrm{ml}$, add $10 \mu \mathrm{l}$ to the same volume of loading buffer and mix well, boil at $95^{\circ}$ for 5 min, quickly spot the sample to the sample hole, 80 $\mathrm{V}, 30 \mathrm{~min}$. When the mixture of sample and loading buffer begins to enter the concentrated gel, adjust the voltage to $180 \mathrm{~V}$ for $60 \mathrm{~min}$; semi-dry constant pressure $15 \mathrm{~V}$, transfer to Polyvinylidene Fluoride (PVDF) membrane for $1 \mathrm{~h}$; seal at room temperature (usually the blocking solution). For $5 \%$ skimmed milk powder, use $5 \%$ Bovine Serum Albumin (BSA) to detect phosphorylation samples for $1 \mathrm{~h}$; discard the blocking solution, wash the membrane with $1 \times$ tris-buffered saline (TBST), $5 \mathrm{~min} /$ time $\times 3$ times, add the primary antibody, shake overnight at $4^{\circ}$; recover the primary antibody, $1 \times$ wash the membrane with TBST, $5 \mathrm{~min} /$ time $\times 3$ times, add secondary antibody, shake at room temperature for $1 \mathrm{~h}$; discard the secondary antibody and wash the membrane with $1 \times \mathrm{TBST}, 5 \mathrm{~min} / \mathrm{time} \times 3$ times; add chemiluminescent substrate (equal amount of liquid A and B) currently used and prepared, exposed and imaged with a chemiscope mini imaging system with a chemiluminescence analyzer.

\section{Statistical processing:}

All statistical analysis was performed by Statistical Package For The Social Sciences (SPSS) 20.0. All measurement data are expressed as mean \pm Standard Deviation (SD) $(\mathrm{x} \pm \mathrm{s})$. One-way analysis of variance and Lysergic acid Diethylamide (LSD) were used to test for differences. $p<0.05$ indicates that the difference is statistically significant.

\section{RESULTS AND DISCUSSION}

The effect of anisomycin, an activator of p38 MAPK pathway on the effect of VPA+DAC on the migration and invasion of SMMC-7721 cells is shown in fig. 1. The figure shows that compared with the control group, the SMMC-7721 cell migration rate and the number of transmembrane cells in the VPA+DAC group were significantly reduced $(p<0.05)$, which is consistent with the results of previous studies, while the $\mathrm{VPA}+\mathrm{DAC}+\mathrm{SB} 203580$ group of SMMC-7721 cells, the migration rate and the number of transmembrane cells were significantly higher than that of the VPA+DAC group $(\mathrm{p}<0.05)$, indicating that the activator anisomycin can reduce the ability of VPA+DAC to regulate the migration and invasion of liver cancer cells. 
A

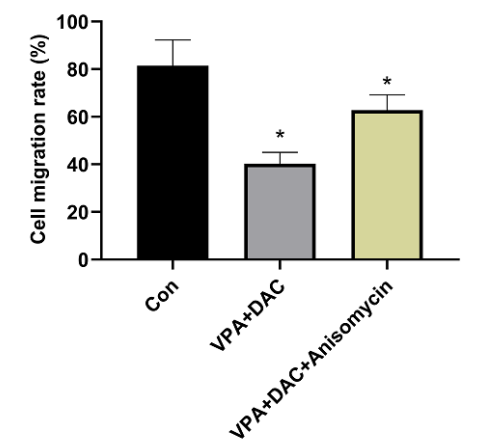

B

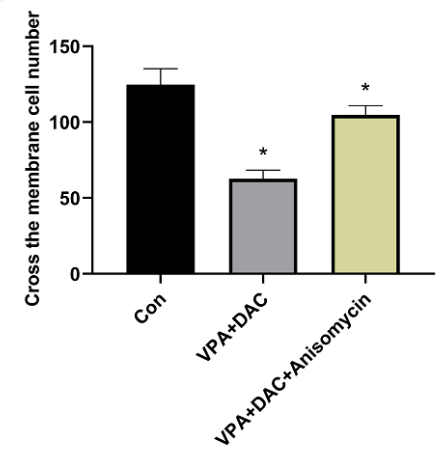

C

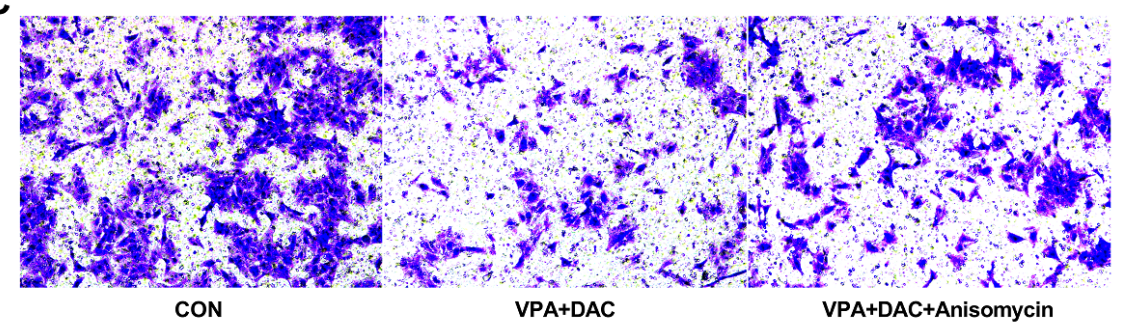

Fig. 1: Transwell detects SMMC-7721 cell migration rate and cell invasion ability (A) migration rate; (B and C) cell invasion ability

The effect of the activator anisomycin on the expression of p38 MAPK/Hsp27 and its phosphorylation level messenger RNA (mRNA) in SMMC-7721 cells treated with VPA+DAC is shown in fig. 2. Fig. 2A showed that the mRNA expression level of p38 MAPK in SMMC-7721 cells in the VPA+DAC group and the $\mathrm{VPA}+\mathrm{DAC}+\mathrm{SB} 203580$ group was significantly lower than that in the control group $(p<0.05)$, while the mRNA expression level of p38 MAPK in the cells in the VPA+DAC+SB203580 group was significantly higher than that in the VPA+DAC group $(p<0.05)$; the results are shown in fig. 2B which are consistent with the results in fig. 2A. The mRNA expression level of phosphorylated p38 MAPK (p-p38 MAPK) in the cells of the VPA+DAC group and the VPA+DAC+SB203580 group was significantly lower than that of the control group $(\mathrm{p}<0.05)$ and the mRNA expression level of p-p38MAPK in the cells of the VPA+DAC+SB203580 group was significantly higher than that of the $\mathrm{VPA}+\mathrm{DAC}$ group $(\mathrm{p}<0.05)$; fig. $2 \mathrm{C}$ and fig. $2 \mathrm{D}$ showed that the VPA+DAC group and VPA+DAC+SB203580 group were significantly lower than those in the control group $(\mathrm{p}<0.05)$ and the expression levels of Hsp27 and p-Hsp27 in the cells of the VPA+DAC+SB203580 group were significantly higher than those in the $\mathrm{VPA}+\mathrm{DAC}$ group $(\mathrm{p}<0.05)$. It shows that the activator anisomycin can significantly enhance the expression of p38 MAPK/Hsp27 and its phosphorylated form mRNA in SMMC-7721 cells treated with VPA+DAC.
The effect of the activator anisomycin on the expression of p53 mRNA in SMMC-7721 cells treated with VPA+DAC is shown in fig. 3. The expression level of p53 mRNA in SMMC-7721 cells in the VPA+DAC group was significantly higher than that in the control group ( $\mathrm{p}<0.05)$. The expression level of p53 mRNA in SMMC-7721 cells in the VPA+DAC+SB203580 group was significantly higher than that in the VPA+DAC group ( $\mathrm{p}<0.05)$. It shows that the activator anisomycin improves the ability of VPA+DAC to increase the expression level of p53 mRNA.

The effect of the activator anisomycin on the expression of E-cadherin and vimentin proteins in SMMC-7721 cells treated with VPA+DAC is shown in fig. 4. It can be seen from the figure that the E-cadherin in SMMC7721 cells in the control group is the lowest, the E-cadherin protein expression in the VPA+DAC group is significantly higher than that in the control group $(\mathrm{p}<0.05)$ and the E-cadherin protein expression in the $\mathrm{VPA}+\mathrm{DAC}+\mathrm{SB} 203580$ group is obvious, it was lower than the VPA+DAC group $(\mathrm{p}<0.05)$; while the vimentin protein expression in SMMC-7721 cells in the control group was the highest, the vimentin protein expression in the VPA+DAC group was significantly lower than that in the control group $(p<0.05)$ and vimentin in the $\mathrm{VPA}+\mathrm{DAC}+\mathrm{SB} 203580$ group The protein expression was significantly higher than that of the VPA+DAC group $(p<0.05)$. It shows that the activator anisomycin attenuates the ability of VPA+DAC to increase E-cadherin and decrease vimentin protein expression. 
A

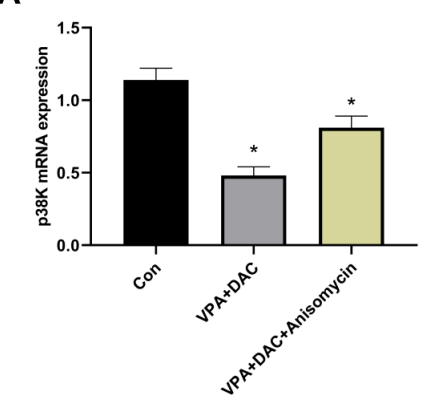

C

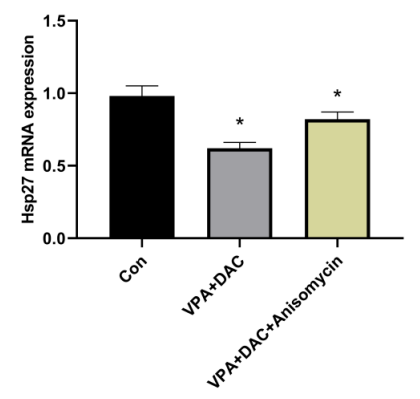

B

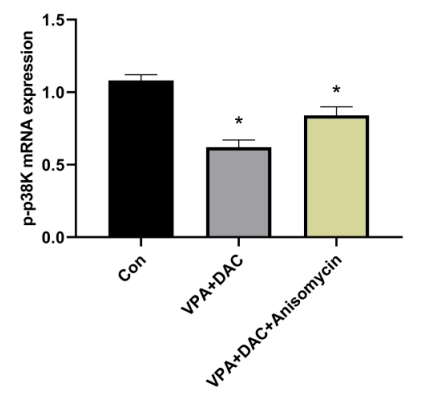

D

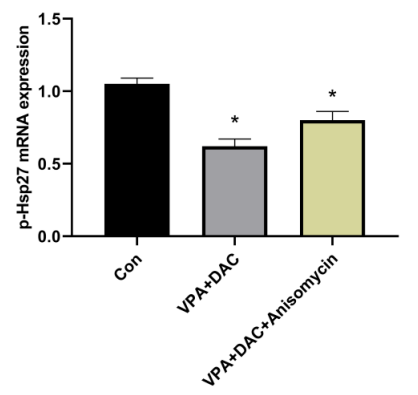

Fig. 2: The effect of the activator anisomycin on the expression of p38 MAPK/Hsp27 (A) p38 MAPK; (B) p-p38 MAPK; (C) Hsp27; (D) p-Hsp27)

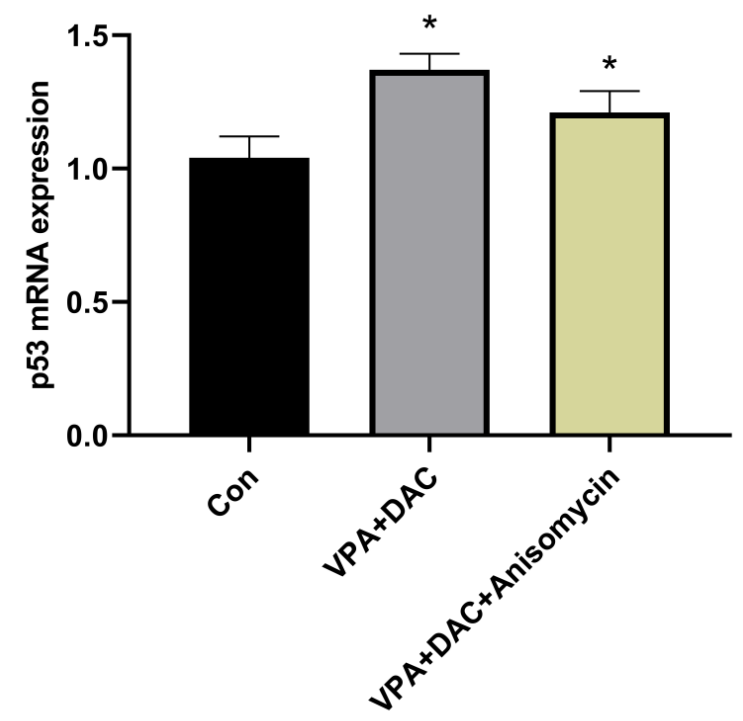

Fig. 3: The effect of activator anisomycin on p53 expression

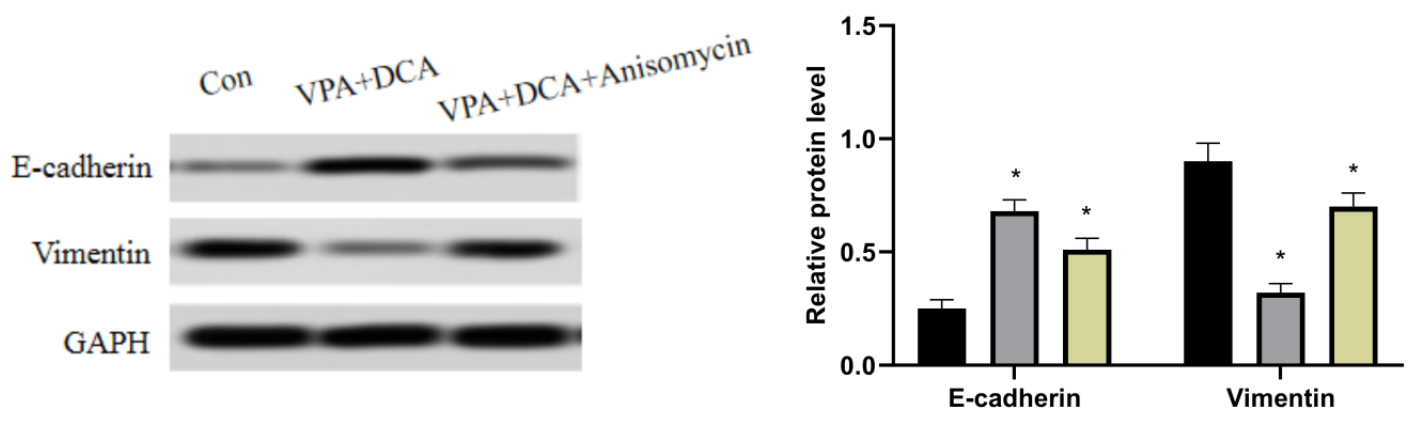

Fig. 4: The effect of activator anisomycin on cell EMT, (ש ) Control; (ש) VPA+DAC; ( $(\square)$ VPA+DAC+Anisomycin 
Our previous studies have shown that the use of VPA combined with DAC can enhance cell migration and invasion. The changes in cancer cell migration and invasion capabilities are closely related to the progress of cancer. In order to clarify the mechanism of VPA combined with DAC in the treatment of cancer, we have discussed the related mechanisms of invasion.

Epidermal Hsp27 is mainly involved in regulating cell growth, differentiation and tumorigenesis. High levels of Hsp27 have been shown to protect cells from stress-induced cell damage ${ }^{[27]}$ and help to increase the resistance to chemotherapeutics during the treatment of solid tumors ${ }^{[28,29]}$. In addition, the expression of Hsp27 is also closely related to the differentiation process of keratinocytes in culture and in vivo ${ }^{[30]}$. Therefore, the expression of Hsp27 is low in poorly differentiated epidermal tumors (such as basal cell carcinoma, squamous cell carcinoma) ${ }^{[31-33]}$ showed that Hsp27 is involved in the keratinization process and may act as a molecular chaperone for the envelope of keratinocytes.

As a substrate of Mitogen-Activated Protein KinaseActivated Protein (MAPKAP) kinases 2 and 3, Hsp27 can be phosphorylated by p38 MAPK $\alpha / \beta$ under various external stimuli ${ }^{[34]}$. Phosphorylated Hsp27 can induce interruption of Hsp27 oligomerization, leading to the decrease of chaperone activity, regulating some functions of cells, such as cell proliferation, differentiation, death and migration ${ }^{[35]}$. Thiers $\mathrm{BH}$, stated that inhibiting the p38/MAPK pathway can inhibit the growth of Colorectal Cancer (CRC) cells and induce apoptosis ${ }^{[36]}$. Research shows that the increase of the phosphorylation level of p38 MAPK, MAPKactivated protein kinase-2 (MK2) and Hsp27 can enhance cell migration and interfere with the apoptotic signal cascade and inhibit cell apoptosis ${ }^{[37]}$. In addition, multiple studies have shown that the transcriptional activity of p53 is regulated by Hsp2 $7^{[38,39]}$.

Therefore, we added the p38 MAPK pathway activator anisomycin to the SMMC-7721 cells treated with $\mathrm{VPA}+\mathrm{DAC}$ and tested the migration and invasion ability of liver cancer cells SMMC-7721 through the transwell test finding that the activator anisomycin attenuated the VPA + DAC reduction in liver cancer. The detection results of p38 MAPK pathway and its phosphorylation level and p53 expression in liver cancer cell SMMC-7721 showed that compared with the control, liver cancer cell SMMC-7721, p38 MAPK and p-p38 MAPK in liver cancer cell SMMC7721 treated with VPA+DAC, the expression levels of Hsp27 and p-Hsp27 were significantly reduced.
VPA+DAC could weaken the phosphorylation of p38 MAPK/Hsp27, while the expression level of p53 was significantly increased $(p<0.05)$, which may be related to the reduction of liver cancer cell SMMC7721 migration and invasion ability is related. It was found that the activator anisomycin attenuated the ability of VPA + DAC to reduce the phosphorylation of p38 MAPK/Hsp27 $(\mathrm{p}<0.05)$ and the expression level of p53 was significantly reduced compared with the VPA+DAC treatment group $(\mathrm{p}<0.05)$ by adding the $\mathrm{p} 38$ MAPK activator anisomycin. P53 is an important tumor suppressor ${ }^{[40]}$. The study of hepatocellular carcinoma and intrahepatic bile ducts in mice lacking p53 in liver cells under oxidative stress conditions confirmed that cancer is accelerated ${ }^{[41,42]}$. Our results indicate that the combination of VPA and DAC may activate $\mathrm{p} 53$ through p38 MAPK/Hsp27, thereby affecting the migration and invasion of liver cancer cells, which is consistent with the research results of Tian $\mathrm{L}$ in colon cancer. The results show that Taurine Upregulated Gene 1 (TUG1) can promote the occurrence and development of colon cancer and the occurrence of EMT, which is achieved by activating the $\mathrm{p} 38 \mathrm{MAPK} / \mathrm{Hsp} 27$ pathway ${ }^{[37]}$.

EMT is a process that promotes the excessive development of epithelial cells to mesenchymal cells with migration ability participating in a variety of physiological and pathological processes, such as embryogenesis, body development, wound healing and tissue organ fibrosis ${ }^{[43]}$. EMT has an important impact on the occurrence and development of tumors which can enhance cell motility and promote cell invasion and metastasis of cancer progression. Recent studies have shown that not all cancers are associated with EMT and EMT plays an important role in the development of liver cancer ${ }^{[44]}$. In addition, EMT can also promote cancer cells to develop resistance to radiotherapy and chemotherapy or drug therapy and reduce the therapeutic effect. Therefore, inhibiting EMT during cancer treatment can enhance the sensitivity of treatment and maintain effective treatment. In order to explore the degree of EMT in liver cancer cell SMMC-7721 treated with sodium valproate combined with DAC, we measured the protein expression levels of E-cadherin and vimentin. The results showed that compared with the control group SMMC-7721, VPA+DAC, the expression level of E-cadherin in the liver cancer cell SMMC-7721 treated with DAC was significantly increased and the expression level of vimentin was significantly reduced. The expression level of E-cadherin in the activated p38 MAPK group was significantly lower than that in the VPA+DAC treatment group and the expression 
level of vimentin was significantly higher than that of VPA+DAC. The DAC treatment group showed that VPA+DAC treatment can reduce the occurrence of EMT in liver cancer cells SMMC-7721. Activation of p38 MAPK expression can reduce the effect of VPA and DAC and combined use reduce the occurrence of EMT.

E-cadherin, an epithelial marker protein and a bridge for cell adhesion, its decrease in expression level can promote the occurrence of EMT by activating winglessrelated integration site $(\mathrm{Wnt}) / \beta$-catenin downstream factors, thereby mediating the migration of cancer cells and promoting cancer progression ${ }^{[45]}$. E-cadherin is usually considered as a tumor suppressor protein. As an interstitial marker protein, vimentin is like E-cadherin, changes in which expression level are a sign of EMT ${ }^{[46]}$. However, other studies have shown that E-cadherin can promote the proliferation of metastatic cells ${ }^{[47]}$, which may be caused by close relationship between the regulation mechanism of the EMT process and the internal environment. The study showed that even under the condition of p38 MAPK activation, the knockout of Hsp27 inhibited the migration of glioblastoma cells $^{[48]}$. Hsp27 is a downstream effector of p38 MAPK and the expression of Hsp27 itself may play a key role in the migration of glioblastoma cells induced by phorbol. This may be due to the fact that p38 MAPK has multiple downstream effectors besides Hsp27 and the regulation of cell function by Hsp27 is not limited to cell migration. Therefore, it is needed to further elucidate the molecular mechanism of p38 MAPK/ Hsp27 in regulating the migration of liver cancer cells.

\section{Acknowledgements:}

This work was supported by the 2019 Baoding science and technology plan, self-financing project (No.1941ZF087). Feng Gao and Ji Hong Yang contributed equally to this work. Feng Gao and Yan Geng are considered as co-corresponding authors.

\section{Conflicts of interest:}

The authors declared no conflict of interest.

\section{REFERENCES}

1. Valere A, Garnotel R, Villena I, Guenounou M, Pinon JM, Aubert D. Activation of the cellular mitogen-activated protein kinase pathways ERK, P38 and JNK during Toxoplasma gondii invasion. Parasite 2003;10(1):59-64.

2. Henriques A, Koliaraki V, Kollias G. Mesenchymal MAPKAPK2/HSP27 drives intestinal carcinogenesis. Proc Natl Acad Sci USA 2018;115(24):E5546-55.

3. Ashrafizadeh M, Zarrabi A, Hushmandi K, Kalantari M, Mohammadinejad R, Javaheri $\mathrm{T}$, et al. Association of the epithelial-mesenchymal transition (EMT) with cisplatin resistance. Int J Mol Sci 2020;21(11):4002.

Special Issue 5, 2021

Indian Journal of Pharmaceutical Sciences
4. Nomura N, Nomura M, Sugiyama K, Hamada JI. Phorbol 12-myristate 13-acetate (PMA)-induced migration of glioblastoma cells is mediated via p38MAPK/Hsp27 pathway. Biochem Pharmacol 2007;74(5):690-701.

5. Felisbino MB, Tamashiro WM, Mello ML. Chromatin remodeling, cell proliferation and cell death in valproic acidtreated HeLa cells. PLoS One 2011;6(12):e29144.

6. Benson EA, Skaar TC, Liu Y, Nephew KP, Matei D. Carboplatin with decitabine therapy, in recurrent platinum resistant ovarian cancer, alters circulating miRNAs concentrations: a pilot study. PLoS One 2015;10(10):e0141279.

7. Booth L, Roberts JL, Poklepovic A, Kirkwood J, Dent P. HDAC inhibitors enhance the immunotherapy response of melanoma cells. Oncotarget 2017;8(47):83155-70.

8. Jonak C, Mildner M, Klosner G, Paulitschke V, Kunstfeld $\mathrm{R}$, Pehamberger $\mathrm{H}$, et al. The hsp27 $\mathrm{kD}$ heat shock protein and $\mathrm{p} 38$-MAPK signaling are required for regular epidermal differentiation. J Dermatol Sci 2011;61(1):32-7.

9. Huang C, Jacobson K, Schaller MD. MAP kinases and cell migration. J Cell Sci 2004;117(20):4619-28.

10. Canel M, Serrels A, Frame MC, Brunton VG. E-cadherinintegrin crosstalk in cancer invasion and metastasis. J Cell Sci 2013;126(2):393-401.

11. Cheung KJ, Gabrielson E, Werb Z, Ewald AJ. Collective invasion in breast cancer requires a conserved basal epithelial program. Cell 2013;155(7):1639-51.

12. Ciocca DR, Oesterreich S, Chamness GC, MCGuire WL, Fuqua SA. Biological and clinical implications of heat shock protein 27000 (Hsp27): a review. J Natl Cancer Inst 1993;85(19):1558-70.

13. O'Callaghan-Sunol C, Gabai VL, Sherman MY. Hsp27 modulates p53 signaling and suppresses cellular senescence. Cancer Res 2007;67(24):11779-88.

14. Di HT, Wu XZ, Wang HQ, Chen M, Kong EL, Yu WF, et al. Involvement of the p38 MAPK-pHsp27 pathway in vascular hyporeactivity induced by obstructive jaundice in rats. Biomed Pharmacother 2020;121:109304.

15. Ghafouri-Fard S, Tamizkar KH, Hussen BM, Taheri M. MicroRNA signature in liver cancer. Pathol Res Pract 2021;219:153369.

16. Heers H, Stanislaw J, Harrelson J, Lee MW. Valproic acid as an adjunctive therapeutic agent for the treatment of breast cancer. Eur J Pharmacol 2018;835:61-74.

17. Huang J. Current developments of targeting the p53 signaling pathway for cancer treatment. Pharmacol Ther 2020;220:107720.

18. Kindas-Mugge I, Trautinger F. Increased expression of the $\mathrm{M}$ (r) 27,000 heat shock protein (hsp27) in in vitro differentiated normal human keratinocytes. Cell Growth Differ 1994;5(7):777-81.

19. Johnson GL, Lapadat R. Mitogen-activated protein kinase pathways mediated by ERK, JNK, and p38 protein kinases. Science 2002;298(5600):1911-2.

20. Kampinga HH, Hageman J, Vos MJ, Kubota H, Tanguay $\mathrm{RM}$, Bruford EA, et al. Guidelines for the nomenclature of the human heat shock proteins. Cell Stress Chaperones 2009;14(1):105-11.

21. Kar R, Jha NK, Jha SK, Sharma A, Dholpuria S, Asthana N, et al. A "NOTCH" deeper into the epithelial-to-mesenchymal transition (EMT) program in breast cancer. Genes 2019;10(12):961. 
22. Kato T, Murata D, Anders RA, Sesaki H, Iijima M. Nuclear PTEN and p53 suppress stress-induced liver cancer through distinct mechanisms. Biochem Biophys Res Commun 2021;549:83-90.

23. Kostenko S, Moens U. Heat shock protein 27 phosphorylation: kinases, phosphatases, functions and pathology. Cell Mol Life Sci 2009;66(20):3289-307.

24. Kulikov R, Letienne J, Kaur M, Grossman SR, Arts J, Blattner C. Mdm2 facilitates the association of $\mathrm{p} 53$ with the proteasome. Proc Natl Acad Sci USA 2010;107(22):10038-43.

25. Kyriakis JM, Avruch J. Mammalian mitogen-activated protein kinase signal transduction pathways activated by stress and inflammation. Physiol Rev 2001;81(2):807-69.

26. Li W, Kang Y. Probing the fifty shades of EMT in metastasis. Trends Cancer 2016;2(2):65-7.

27. Ferlay J, Soerjomataram I, Dikshit R, Eser S, Mathers C, Rebelo $\mathrm{M}$, et al. Cancer incidence and mortality worldwide: sources, methods and major patterns in GLOBOCAN 2012. Int J Cancer 2015;136(5):E359-86.

28. Ma C, Zhang Q, Greten TF. MDSCs in liver cancer: A critical tumor-promoting player and a potential therapeutic target. Cell Immunol 2021;361:104295.

29. Marcel V, Catez F, Diaz JJ. p53, a translational regulator: contribution to its tumour-suppressor activity. Oncogene 2015;34(44):5513-23.

30. Ozen C, Yildiz G, Dagcan AT, Cevik D, Ors A, Keles U, et al. Genetics and epigenetics of liver cancer. N Biotechnol 2013;30(4):381-4.

31. Li P, Li Q, Zhang Y, Sun S, Liu S, Lu Z. MiR-422a targets MAPKK6 and regulates cell growth and apoptosis in colorectal cancer cells. Biomed Pharmacother 2018;104:832-40.

32. Pichon S, Bryckaert M, Berrou E. Control of actin dynamics by p38 MAP kinase-Hsp27 distribution in the lamellipodium of smooth muscle cells. J Cell Sci 2004;117(12):2569-77.

33. Robitaille H, Simard-Bisson C, Larouche D, Tanguay RM, Blouin R, Germain L. The small heat-shock protein Hsp27 undergoes ERK-dependent phosphorylation and redistribution to the cytoskeleton in response to dual leucine zipper-bearing kinase expression. J Invest Dermatol 2010;130(1):74-85.

34. Rocha MA, Veronezi GM, Felisbino MB, Gatti MS, Tamashiro WM, Mello ML. Sodium valproate and 5-aza-2'-deoxycytidine differentially modulate DNA demethylation in G1 phasearrested and proliferative HeLa cells. Sci Rep 2019;9(1):1-2.

35. Tanaka T, Iino M, Goto K. Sec6 enhances cell migration and suppresses apoptosis by elevating the phosphorylation of $\mathrm{p} 38$ MAPK, MK2, and HSP27. Cell Signal 2018;49:1-6.

36. Thiers BH. Pemphigus. J Am Acad Dermatol 1981;4(5):603-5.

37. Tian L, Zhao ZF, Xie L, Zhu JP. Taurine up-regulated 1 accelerates tumorigenesis of colon cancer by regulating miR26a-5p/MMP14/p38 MAPK/Hsp27 axis in vitro and in vivo. Life Sci 2019;239:117035.
38. Trautinger F, Kindas-Mugge I, Dekrout B, Knobler RM, Metze D. Expression of the $27-\mathrm{kDa}$ heat shock protein in human epidermis and in epidermal neoplasms: an immunohistological study. Br J Dermatol 1995;133(2):194-202.

39. Trautinger F, Kokesch C, Herbacek I, Knobler RM, KindasMugge I. Overexpression of the small heat shock protein, hsp27, confers resistance to hyperthermia, but not to oxidative stress and UV-induced cell death, in a stably transfected squamous cell carcinoma cell line. J Photochem Photobiol B 1997;39(1):90-5.

40. Veronezi GM, Felisbino MB, Gatti MS, Mello ML, Vidal BD. DNA methylation changes in valproic acid-treated HeLa cells as assessed by image analysis, immunofluorescence and vibrational microspectroscopy. PLoS One 2017;12(1):e0170740.

41. Fang JY, Richardson BC. The MAPK signalling pathways and colorectal cancer. Lancet Oncol 2005;6(5):322-7.

42. Welsh MJ, Gaestel M. Small heat-shock protein family: function in health and disease. Ann N Y Acad Sci1998;851:2835 .

43. Wheler JJ, Janku F, Falchook GS, Jackson TL, Fu S, Naing A, et al. Phase I study of anti-VEGF monoclonal antibody bevacizumab and histone deacetylase inhibitor valproic acid in patients with advanced cancers. Cancer Chemother Pharmacol 2014;73(3):495-501.

44. Zhang Y, Zhang Y, Li M, Meng F, Yu Z, Chen Y, et al. Combination of SB431542, CHIR99021 and PD0325901 has a synergic effect on abrogating valproic acid-induced epithelial-mesenchymal transition and stemness in HeLa, 5637 and SCC-15 cells. Oncol Rep 2019;41(6):3545-54.

45. Yasuda T. MAP kinase cascades in antigen receptor signaling and physiology. Curr Top Microbiol Immunol 2016;393:21131.

46. Li Y, Zhang T, Qin S, Wang R, Li Y, Zhou Z, et al. Effects of UPF1 expression on EMT process by targeting E-cadherin, $\mathrm{N}$-cadherin, Vimentin and Twist in a hepatocellular carcinoma cell line. Mol Med Rep 2019;19(3):2137-43.

47. Yuan JH, Yang F, Wang F, Ma JZ, Guo YJ, Tao QF, et al. A long noncoding RNA activated by TGF- $\beta$ promotes the invasionmetastasis cascade in hepatocellular carcinoma. Cancer Cell 2014;25(5):666-81.

48. Zheng LZ, Chen SZ. shRNA-induced knockdown of the SPERT gene inhibits proliferation and promotes apoptosis of human colorectal cancer RKO cells. Oncol Rep 2018;40(2):813-22.

This is an open access article distributed under the terms of the Creative Commons Attribution-NonCommercial-ShareAlike 3.0 License, which allows others to remix, tweak, and build upon the work non-commercially, as long as the author is credited and the new creations are licensed under the identical terms

This article was originally published in a special issue, "Diagnostic and Therapeutic Advances in Biomedical Research and Pharmaceutical Sciences"

Indian J Pharm Sci 2021:83(5) spl issue "140-147" 